\title{
RELIGIÓN DEL PUEBLO Y MISIÓN SALVIFICA DE LA IGLESIA
}

Diego Irarrázaval, CSC.

Me han inspirado modelos que articulan la espiritualidad de la gente común y el ser eclesial'. El 20 de mayo de 1975 Wilfredo Alarcón -de rodillas en el lecho del rio Cautin- es baleado en una pierna, el pecho y la cabeza; ("cagó el cura" dijo el jefe militar, pero las aguas le arrastraron y ¡ha sobrevivido!). Se dedicó a tallar Cristos con raices de avellano que recogía en las orillas del rio "donde me fusilaron"; y añade: "me cuesta mucho rezar pero he descubierto que ésta (labor de tallar) es también una forma de orar". Él amaba a Cristo sin una oración estereotipada. Asi vive mucha gente. Otro modelo: en Arica, Ignacio Vergara ejercia la condición de trabajador; escribió a los jesuitas dando "gracias a mi Señor" por ser acogido por el "pueblo de la tierra" que le ha "enseñado... los valores del Reino de Dios". Ha sido evangelizado por los últimos de la tierra.

Estos son casos especiales, fascinantes. No son asi los claro-oscuros de cada día. Uno constata el impasse entre la población creyente y los organismos eclesiales; además, crece la indiferencia hacia la actividad eclesial. Lo ha consignado el último Sinodo de Santiago?. Esta realidad duele. (Nuestra agenda teológica podria priorizar la escasa credibilidad que tiene la Iglesia como medio de salvación: esto no ocurre en una población increyente sino más bien polifacéticamente espiritual).

Cito testimonios de W. Alarcón e I. Vergara, recogidos por M. JORDA. Memoria de dos curas asesinados, Santiago 1998, p. 114; y VV.AA., Ignacio Vergara sj sacerdote obrero, Santiago, Centro de Espiritualidad Ignaciana, s/f., pp. 17-18.

El noveno Sinodo de Santiago (en texto anexo al documento de trabajo) constataba: "búsqueda de Dios. Expresada de muchas maneras.. movimientos apostólicos y de espiritualidad y fitürgica... crecimiento de los evangélicos. y de las sectas y de otras manifestaciones de bisqueda de lo trascendente". y en cuento a la Iglesia Católica "... distanciamiento de mucha gente en cuanto a su vivencia de Fe y en cuanto al seguimiento de sus enseñanzas sociales y morales". ARZOBISPADO DE SANTIAGO. Serie Documentos, Mirada a la realidad, 1995, p. 18. 
Por otra parte. me incomoda tener que demostrar el valor de la religion popular. Convendria examinar religiosidades -e incoherencias- en diversos sectores de Iglesia. La vivencia de las èlites y de portavoces de la Iglesia, también merece un estudio critico. Pero me han pedido que reflexione sobre el pueblo.

En la temática de religión y salvación hay que tener presente lo fundamental. Pueblo y personas somos "llamados a la salvacion por la gracia de Dios" (LG 13; Cfr NA 1). No es un asunto eclesiocentrado ni sectario, la Iglesia "promueve la gloria de Dios y la salvación de todos" (LG 16). La misión es Trinitaria; la Iglesia ora y trabaja para que el "mundo se incorpore al Pueblo de Dios. Cuerpo del Señor y Templo del Espiritu Santo... $Y$ se rinda honor y gloria al Creador y padre universal" (LG 17). En este marco se desenvuelve nuestra reflexión.

Ahora bien. ¿cuál es la conexión entre la voluntad salvifica universal de Dios, cuya señal indefectible es la Iglesia de Jesucristo y los elementos salvíficos en las religiones de la humanidad ( $\mathrm{y}$ en concreto en religiosidades en Chile)? A mi modo de ver. lo primero y lo segundo se complementan y no constituyen disyuntivas.

A lo largo de estas décadas. en América Latina redescubrimos que la Iglesia es sacramento de liberación integral. al servicio de la Basileia. Ella es pueblo de Dios con jerarquia, ministerios, carismas, que han optado solidariamente con el pobre. Lo que parece más dificil es acoger y llevar a cabo la salvación de manera inculturada e in-religionada. En otras palabras. no es fácil articular religión del pueblo y misión salvifica de la Iglesia. A ello dedico estas páginas.

\section{A. Cuestiones Disputadas}

He anotado la poca credibilidad del servicio eclesial a la salvación. Esto ocurre en nuestro escenario afligido por la pobreza y la infelicidad moderna; y a la vez, con muchas energias espirituales. ¿Por que pasa todo esto? Son temas a debatir.

Por mi parte, voy a puntualizar seis cuestiones que afectan a la religiosidad y la iglesia.

- La auto-salvación contemporánea. Esta actitud es sustentada por varios factores: ideologia yo-ista en el mercado y los medios de comunicación, la subjetividad moderna y posmoderna, difusión de terapias de auto-estima y auto-ayuda, orientación de la religión y la espiritualidad hacia el bienestar personal, reacción ante la vorágine de imágenes y la incertidumbre del cambio de época. Pues bien, la religiosidad contemporánea ¿tiende a la auto-salvación? y ¿se aleja de la Otreidad trascendente? Estas cuestiones no provienen de la vivencia 
religiosa, sino del cambiante escenario mundial; pero penetran lo especificamente sagrado.

- El status de lo sagrado. Nos envuelve un carnaval de demandas y ofertas religiosas y espirituales, que son interiorizadas de manera ecléctica e inmediatista. (Esto lo constatamos en el terreno cristiano; por ejemplo, la adhesión a movimientos emergentes y a lideres novedosos.) En la larga historia de la humanidad, lo sagrado ha dado sentido y nos ha conectado con uno mismo, el medio ambiente. la comunidad, la divinidad. En sociedades que se definen como "desarrolladas", Io sagrado tiende a ser cada vez más un objeto de consumo, descartable y de felicidad pasajera. Cabe discutir las sacralizaciones de hoy, en la economía, el trato social, los juegos de azar, la religiosidad "al paso" y tanto más.

- Un Salvador y muchas religiones. ¿Qué significan y qué pueden hacer hoy los 2 billones de cristianos con respecto a los 4 billones de no cristianos? Una actitud absoluta (explicada de manera cristocéntrica). Esta actitud la encontramos en la Dominus lesus (el relativismo en ns. 4,5,22: la verdad en ns 4,5.7,22 y la curiosa expresión: "salvación de todos por el conocimiento de la verdad"). Es saludable debatir la obsesión por un tipo de verdad y el sacralizar ciertos lenguajes teológicos (que ison relativos!) al condenar el relativismo. Ésta postura tiende a ser totalitaria y devastadora. En cuanto al relativismo, resulta siendo incoherente ya que al postular el relativismo se auto-constituye de una manera dogmática. Más bien vale dedicarse a dilucidar el sentido de Cristo Salvador para pueblos con diversas religiones y espiritualidades.

- Evaluación de la religión popular. Muchos elogian a autoridades de iglesia que han pasado del rechazo al discernimiento de maneras como la población vive su fe. Ciertamente es bueno dejar atrás posturas de exclusión y agresión. Pero la evaluación suele ser superficial y dicotómica. Un ejemplo es el bien intencionado documento de Puebla que nos incentiva a ser lúcidos, pero lo hace con el simplista esquema de positivo/negativo (DP 454-456). Pongo un caso: el "sentido de la providencia de Dios"; nos pone en Sus manos, pero también es usado como barniz para tapar la injusticia social y racial. Por lo tanto, vale debatir una religiosidad polisémica; y ver cómo evaluar las dimensiones salvíficas en la religiosidad.

- In-religionación de la fe cristiana. Nos habiamos acostumbrado a un tajante deslinde entre fe (de Dios) y religion (del imaginario humano). Gracias a Dios hoy muchas personas reconocemos que la fe cristiana tiene mediaciones religiosas y que las religiones tienen señales de la acción del Espiritu de Cristo. Son logros importantes. Sin embargo, el afán in-culturador no suele ir acompañado del afán in-religionador. Dialogamos con las culturas y no con las religiones. Se reproduce el 
viejo y contradictorio esfuerzo de reemplazar "otra" religión por la "nuestra" (en un esquema de falsedad/verdad). Cabe pues discutir como es inreligionado el acontecimiento de Cristo

- Lo conceptual versus lo simbólico. ¿Por qué son puestos uno contra el otro? ¿Por que lo primero suele ser entendido como superior con respecto a lo segundo? ¿La gente "primitiva" seria más simbólica y la civilización occidental -iplagada de guerras!- nos haria más racionales? Todo esto afecta nuestra temática. La religión popular seria más ritual y simbólica; la misión eciesial seria más docente $e$ inteligente. A mi parecer la religiosidad tiene grandes recursos de sabiduria, por un lado $y$, por otro lado, la razón moderna favorece la ciencia critica (sin ser universal ni carente de mitos). Ahora bien. al debatir el sentido de la misión eclesial a favor de la Salvación, redescubrimos un lenguaje simbólico; éste lenguaje caracteriza la Buena Nueva de Jesucristo y de su Iglesia.

Estos y otros puntos suscitan controversias, e indican que nuestro tema no se presta a ingenuas concordancias, ni tampoco se presta a dicotomias de lo verdadero y lo falso. lo salvado y lo incompleto.

\section{B. Catolicismo de Salvación}

Lo vivido -a lo largo de los años- alimenta mis convicciones. He reflexionado y colaborado en la evangelización de la compleja, cambiante, pluriforme religión de la gente común. Ella además me transforma, gracias a su fe gozosa, su ética. su abertura al Misterio. Estas convicciones subyacen lo dicho a continuación.

¿Qué aporta la religión popular a la comprensión de la misión salvifica de la Iglesia? Es un interrogante inmenso. Me limito a unos rasgos del catolicismo en el sur de nuestro continente ${ }^{3}$. Comento seis rasgos generales, sin entrar en los detalles y ricos matices de esta realidad eclesial.

3 Recomiendo umos trabajus. Encuentros realizados por la Fat:ultad de Teologia de Santiago en 1973, 1977, 1986: Forigrosidad y fe en Amethid Latind, Salliagu. Mundo. 1975: Historia y Mision. Santiago. Mundo, s/f. Teologia y Vidi 1-2. 1987: alli también publico C. JOHANSSON su Refigrosidad popular entre Medellin y Puctia Alnales XLI. 1990. Estudios históricos y sociologicos: F. ALIAGA. La Igiesia en Chile. Santiago, Paulinas. 1989. M. SALINAS. Historia del pueblo de Dios en Chite. Simtiayu. Rehue. 1987; H LAGOS Citsis de la esperanzo, religion y autoritarismo en Chilc. santiago, PRESOR, 1986. VV.AA. Lit retigiosidad mariana en Chite. Santiago. Paulmas. 1992: M. BARRIOS. La uspiritualidad chilena. Santiago. San Pablo, 1994 C. PARKER, Animitas, machis y santiguadoras, Santhago. Rehue, 1992: R. SALAS. Lo Sagrado y lo humano. Santiago an Pablo. 1996. La rica rethgrosidad del morte $J$ KESSEL.

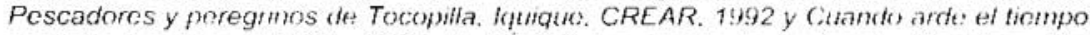
sagrado. ta f'u, HISBOL. 1992: H LOPEZ. La chmito de Amteacotte Samtiago. Def Canto. 1995. Unos ensayos teológicos SELADOC. Religmsidad poptuar iSiamanca: 


\section{En la marginalidad, hay portadores de fe sólida}

La fidelidad y la evangelización son llevadas a cabo por gente discriminada (en la sociedad y a menudo en la iglesia). Me refiero a personas y grupos pobres y con poca instrucción, mujeres, migrantes, sectores mestizos e indigenas, etc. En modos anónimos y cficaces, son protagonistas de la fe (con su dimensión ecłesial). Confian en Dios, ejercen la ayuda mutua y dan testimonios de su Presencia (por ejemplo: decir espontáneamente un "gracias a Dios" y un "Dios te bendiga"). Generalmente son personas laicas y son mujeres. Están en los márgenes y sufren discriminación: pero su fe es sólida, hondamente sabia y misionera.

Por eso la pastoral y teologia más relevantes tienen el sello laical y son elaboradas desde y con sectores cotidianamente discriminados. Esto interpela tanta teologia hecha desde instancias de poder económico, intelectual. eclesiástico. Ello también fortalece a gente postergada. Se trata de la eclesialidad del pueblo pobre, fiel y sabio, a quien Dios ha escogido como portadores de su Amor.

\section{Catolicismo en las culturas y religiosidades}

Las formas católicas se desenvuelven en espacios y tiempos donde es celebrada la salvación dada por Dios a una humanidad pecadora. Ritos y fiestas son polisemicas e inculturadas y a menudo incluyen rasgos de otras religiones populares (un fenómeno que puede ser llamado "sincretismo desde abajo"). Son formas simbióticas ya que el pueblo reúne elementos diferentes a fin de superar carencias y ¡vivir bien! Al ser simbióticas, forjan vida nueva $y$, en menor medida, sacralizan tal cultura y tal religión. Esto lamentablemente si ocurre en mucho fundamentalismo que desde lo propio combate "otras" culturas/religiones.

En varias situaciones palpamos como la comunidad in-cultura la fe cristiana. Cabe también ex-culturar la fe de fuerzas deshumanizantes. Por ejemplo, desligarla de un mercado totalitario. (Al respecto, es alarmante que perspectivas de marketing van penetrando en la pastoral; y esto afecta las creencias populares). Por otro lado, aunque poco se habla de inreligionación de la fe cristiana, esto es llevado a cabo por gente católica que sintoniza y dialoga con varias tradiciones espirituales. Andrés Torres anota que al incorporar elementos de otras religiones, el organismo católico no

Sigueme. 1976): congreso de religiosidad popular Mariana (en Revista Católica. Santiago, 1082, 1989): LUIS MARTINEZ, Evangelización incuiturada y acción del Espiritu Santo en el mundo (Santiago: San Pablo, 1995); y en otras latitudes; VV.AA. Evangelización de la cultura e inculturación del Evangelio (Buenos Aires: Guadalupe. 1988); JUAN CARLOS SCANNONE, Evangelizacion. cultura y teologia (Buenos Aires Guadalupe. 1990); JOSÉ LUIS IDIGORAS, La religión fenómeno popular (Lima Paulinas. 1991): VV AA., Cristo crucificado en los pueblos de America Latina (Quito Abya Yala, 1992): VICTORIANO ZACCHETTO, Imágenes en acción (Quito: Abya Yala. 1999): DIEGO IRARRÁZAVAL. Teologia en la fe del pueblo (San José: DEI, 1999): VICTOR CODINA, O credo dos pobres (Sao Paulo: Paulinas, 1997). 
desaparece "sino por ef contrano croce: chece it path the til abertua al otro. pero en la divecion del Misterio comum".

Hace un momento hablé de ex-culfural. dactil la oprosicon cultural: puede también hablarse de ex religicmar la te poryla para leorientarla hacia Cristo. Existen factores que no son mediacion pata fe simo que parecen manifestar idolatria. Memiono un tipo de clite a Santos (a Rita. Antonio. Judas Tadeo y otros) que supuestamente: solucionan tordo y en especial resuelven lo in los muertos, destulye: of errot. desticmi lis ralaminados, persigue a los

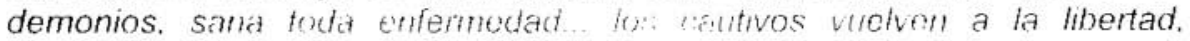
jóvenes y ancianos te invocan y obichun les mombus de que carecen y los

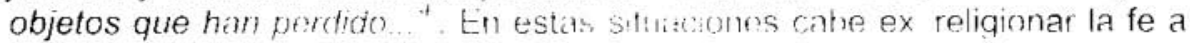
fin de relacionarse con el atutentıco 3 ilvacin, Josticristo

En términos gentates vale thatuin ar si las tiversas religiosidades son senderos de sillvacion cristianis. I sto inficlica desartullar una postura

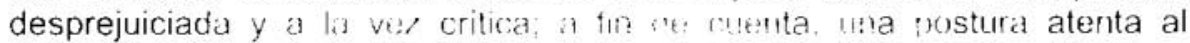
Espiritu de Cristo prestente de maner.a ibsolitis en las trayectorias humanas.

\section{Mucho vinculo y mucha privatización}

La religiosidat catolica en Cibie y un Aménca Latina tiene fuertes tendencias comunitarlas y de compesion ent:e los qobress. Por otro lado prolifera el yo-ismo y int in-solidariad an el terreth espintual. Hay pues grandes ambiguedactess $\vee$ tensiones

Los vinculos sobresalen en tanta asociacion para rezar, estudiar y meditar la fe, realizar obris de bien comin. Hay muchis modos de transmitir espiritualidad en la familia, el vecindario, hi ciudad. Fxisten eficientes lideres locales de la práctica católica (tun devociones catequesis liturgias. instancias de accion social, etc.), e incontables grupos bibhcos, espirituales, comunidades de base y otros modos de vivir con ntros y con-Dios. Algo maravilloso es la generalizada aterición humana y espirituat a personas enfermas. En goneral, existe una vasta red de vincul,s: que suelen no tener un membrete eclessial pero de hecho punen en pricticin el ser eclesial solidario y fiel al Dios; de la vida.

Otra gian lined de fuema es relacunarse crm to siagracto y con el próximo de modo individualista y secrotario. Esto ha crocido en los contextos urbanos y masificados. drmde se sobrediniensioran in ne asidarles yoistas

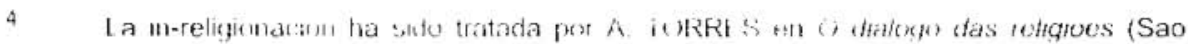

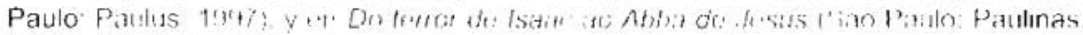
2001). cito si: frit it

5

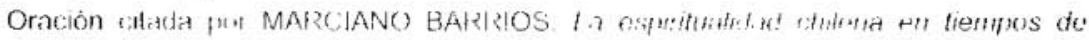

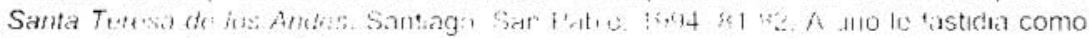

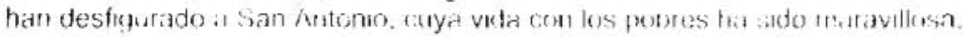


y dónde se multiplican asociaciones cerradas y más o menos intolerantes. También el interior de la Iglesia Católica proliferan yo-ismos espirituales y las prácticas sectarias.

Estos escenarios plantean desafios eclesiológicos. No se avanza con la simple nostalgia hacia el catolicismo tradicional. Si vale retomar sus energias vivas y repensar el ser signo comunitario de la salvación en Cristo. Algunos usan el sugerente lema de ser iglesia "comunidad de comunidades". Puede ser en el sentido de redes de asociaciones, que celebran la fe en Cristo y asumen responsabilidades históricas. Con respecto a sacralizaciones contemporáneas (como es el caso del mercado totalitario y del armamentismo) la misión de la Iglesia es claramente contestataria. En esto y tanto más la Eclesiologia tiene dimensiones proféticas.

\section{Creencias frágiles e innovaciones}

No me detengo en la amplia gama de creencias, ni en las actuales crisis (de increencia e indiferencia). Me impresionan dos asuntos. Grandes sectores católicos de hoy adhieren de modo frágil y esporádico a la Iglesia como institución mediadora de la gracia dada por Dios. Paradojalmente, abundan actitudes de fe en Dios (y referentes sagrados) que conllevan ser salvados mediante signos muy precisos; $y$, algunas personas ven que a ello contribuye la Iglesia y por eso acuden a ella.

Hablando a grandes rasgos, es escasa la creencia en la necesaria mediación eclesial, con sus estructuras y servicios sacramentales. Me refiero a quienes se llaman y son católicos; sin embargo, no son activos en la institución ni interiorizan la misión que le ha dado Jesucristo. Hay pues mucho terreno por cultivar, en el sentido de confianza y participación en la Iglesia que está al servicio del Reino y existe para la gloria de Dios.

He anotado problemas y vacios. Cabe también otra lectura de esos fenómenos. La población católica no práctica una "eclesiolatria" ni una "autocentración eclesial" como ocurre en algunos ámbitos oficiales.

Otro asunto importante es que hoy rebrotan imágenes y convicciones de Iglesia. Tenemos un fecundo imaginario generado en nuestros origenes y la patristica y que vuelve a ser apreciado: pueblo, cuerpo de Cristo, templo del Espiritu, fracción del pan, comunidad carismática, tradición apostólica, esposa de Cristo, madre, communio sanctorum y tanto más. En cada época y también en la actualidad surgen figuras y convicciones; por ejemplo: iglesia que camina en la historia, Samaritana ante sufrimientos en el mundo contemporáneo, comunidad inculturada que festeja la vida. Es necesario afianzar imágenes y fidelidades, para que seamos -no de palabra sino en los hechos- Iglesia sacramento de la salvación del mundo. 


\section{Orientaciones éticas de la pohiacion!}

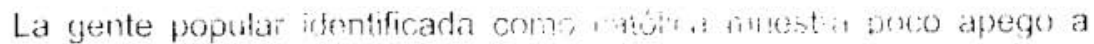

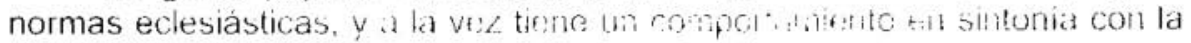
ética del Evangelio. En ulras latitudes. alsians sstunios ian valorado la moral del pueblo'. No esta centradu en regamontos $\vee$ taustions sino en el

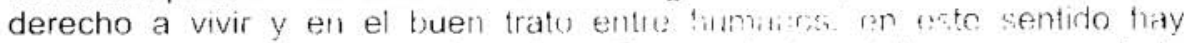
conciencia del pecado y del perdon. (Escic actitus cumtribuye is corregir la obsesión pastoral por ciertas tematicas, secialis, lon sutoros populares ayudan al conjunto de la Iglesia a rederusurir la masist dis oviagelio y del

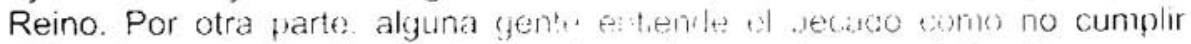
obligaciones rituales (los Santos castignt si fllo in les anole), esto merece un esclarecimiento.

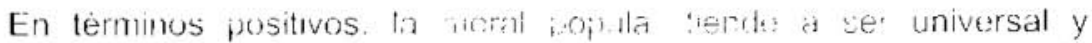
relacional; Carlos Brandau la defino como vivir hen" en dubitos como la

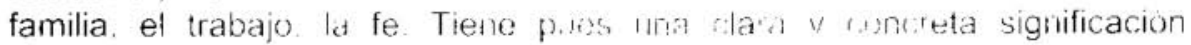
salvifica.

Sin embargo lay muctas sumbris y wadabs La población esta

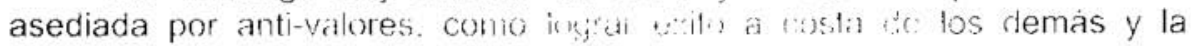
indiferencia y complicidad con la viuenuik que whise al interior del puebio.

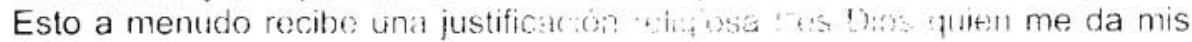
recursos"; los "otros" tienen la culpa to tal wal stc). Vale: pues dar

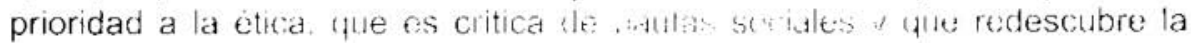
moral del Evangelio para los ticmpos actiates.

\section{Fe con simbolos de salvacioi?}

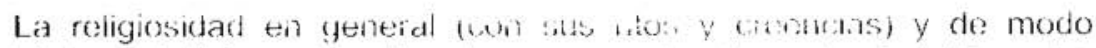

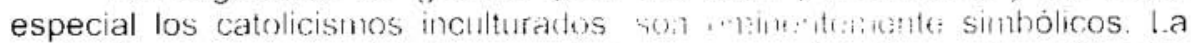
gente tiene gran capacidad para relacionlat tha mikd ul con olra diferente; ella acoge y cultiva senales sensibles de: eabritfes trascendentales. I a sacramentalidad corre por las venas di: la poblation fobre. Todo esto es distinto a practicas que acentian arciones y ionocinientos coirectos o bien ponen acento en lo sagrado segregado do to profailo. o bien un sentirse saivados y repudiar a los pecadores

Se trata de und espirituatidad y una praxis smbilica Dios es amado en realidades concretas y colidianas que themen vitor simbolico. Instancias como el nacimiento y como la muterte culituvan lum ompartir material y vínculos de vida (oracion, risas, plealos, alianzas, compromisos). La ceremonia sacramental en el templo rs indesligable de otros codigos simbólicos en la celebración huriana

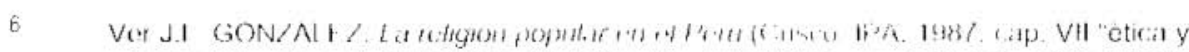

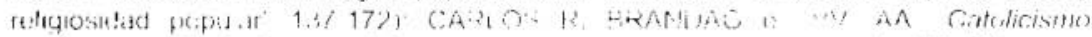

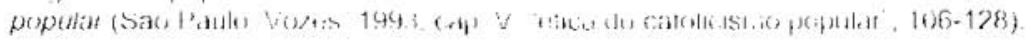


Espero no tergiversar el catolicismo de la gente al describirlo en términos de salvación. Dicho ser católico no está orientado a saber algo de Dios, ni a ser estrictos miembros de la Iglesia, ni a aferrarse a una serie de mandamientos. Claro que hay sabiduria en la fe del pueblo y sus modos de pertenencia eclesiai y su responsabilidad ética. Pero lo principal es la vivencia de salvación que es acogida en formas muy precisas; ésta salvación proviene de Dios y resuelve tribulaciones de cada dia. Se trata de vivencias con calidad simbólica.

\section{UnAS CONCLUSIONES}

Durante décadas la religiosidad de gente sencilla ha sido descalificada por sus abundantes ritos y creencias. No cabe duda que alli, como en cualquier práctica de la fe, muchas cosas requieren un discernimiento, con criterios biblicos y eclesiales. Sin embargo, mucho rito y creencia expresa entre otras cosas- la dimensión simbólica de la fe del pueblo. También ha sido descalificada la manera "pragmática" como la salvación es entendida y vivida por el puebio sencillo. En este asunto (como en lo dicho anteriormente) sufrimos la incomunicación entre élites (que hacen tales descalificaciones) y la comunidad humana con su caminar simbólico hacia Dios.

Retomo nuestra preocupación central. En cuanto a la salvación ¿cómo se relaciona la acción oficial de la iglesia con la religiosidad de gente católica? Para tener sentido salvifico, dicha acción como también esta religiosidad, encuentran su fundamento en Cristo, que es el único camino de salvación. Por lo dicho a lo largo de este trabajo, la primera (acción evangelizadora de la iglesia) no cancela la segunda (religiosidad de la gente), ni la segunda es paralela y alternativa a la primera.

Como católicos creomos que el pueblo de Dios está al servicio de la salvación de la humanidad. Siguiendo el mandato de Cristo y movida por el Espíritu, la Iglesia se hace presente "a todos los seres humanos y pueblos para conducirlos a la fo, a la libertad y a la paz de Cristo... ( y a la vez) el Señor puede conducir por caminos que El sabe a quienes ignoran el Evangelio" (AG 5 y 7). Dicha necesidad y sacramentalidad de la Iglesia no tiene que ser contrapuesta a las religiones existentes en el mundo de hoy.

Esto último ocurre, por ejemplo, cuando la fe es vista como acoger la verdad revelada y las religiones como simples búsquedas de la verdad. Es una problemática planteada en la Dominus lesus'. La realidad en que nos

La distincion entre la fo teologal y la creencia en las otras religiones. Si la fe es la acogida en la gracia de la verdad revelada... la creencia en las otras religiones... que el hombre, en su busqueda de la verdad, ha ideado y creado en su referencia a to Divino $y$ al Absoluto" (CONGREGACIÓN PARA LA DOCTRINA DE LA FE. Dominus lesus. 1) . I (SONZÁt I:Z FAUS advierte que el documento maneja una "noción de 
movemos y la sensibilidad espiritual. nos indica otra cosa. Gracias a la fe. personas y comunidades acogemos la Revelación y la Saivación. con sus mediaciones eclesiales. En cuanto a las religiones (e incluyo a la católica) pueden ser apreciaciones como senderos de verdad y de salvación. en la medida que asi lo dispone la voluntad de Dios que ama a toda la humanidad.

En este sentido puede hablarse de salvacion in-religionada. Ella forma parte de la comprensión de la misión de la Iglesia, que dialoga con las religiones y descubre en ellas señales de Dios. Dicho concepto de salvación in-religionada es también un reconocimiento de Jesucristo como camino/verdad/vida para toda la humanidad (ya no es propiedad privada de un grupo selecto). Podemos pues afirmar simultaneamente la salvacion en Cristo y los valores simbólicos en la religiosidad popular.

En estos terrenos la labor teológica tiene responsabilidades delicadas y audaces. Ella puede interactuar con la simbologia y la pragmática del pueblo. Ella no debe encerrarse en interesantes distinciones entre fe y religión, entre iglesia y catolicismo de la gente. Más bien interesa como la humanidad es salvada por Dios; e interesan las formas simbólicas como se desenvuelve la salvacion. En cuanto a mi actitud. me preocupa hacer reflexiones en comunión con la fe del pueblo pobre y su participación en la Iglesia.

vertial mis grequ que bihhca" que es siempre verdad atuenti y acompainada de la

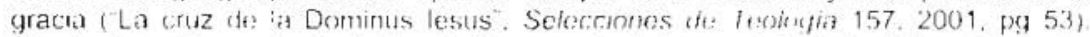
Anado el problemat de: cierta "verdad" separada de la accefida te lis Salvacion sogin designios misterikos de Doos, que a toda persona hace partutapar en la pascua de: Cristo. 